\title{
Forkhead Box M1 promotes the growth and tube formation of human malignant meningioma cells via the aryl hydrocarbon receptor signaling pathway
}

\author{
Qiang $\mathrm{Wu}^{1}$, Jingjing Zheng ${ }^{1}$, Changwu Dou ${ }^{1}$, Songtao $\mathrm{Qi}^{2}$ \\ ${ }^{1}$ Department of Neurosurgery, Affiliated Hospital of Inner Mongolia Medical University, Hohhot, Inner Mongolia Autonomous Region, \\ China, ${ }^{2}$ Department of Neurosurgery, Nanfang Hospital, Southern Medical University, Guangzhou, Guangdong Province, China
}

\begin{abstract}
Introduction: Forkhead Box M1 (FOXM1) and aryl hydrocarbon receptor (AHR) signaling pathway participate in meningioma development, but their correlation was inadequately studied. The study is aimed to uncover their functions and correlation in malignant meningioma.

Material and methods: Quantitative real-time polymerase chain reaction ( $q R T-P C R$ ) was performed to detect FOXM1 expression in malignant meningioma and adjacent tissues. The viability, proliferation, apoptosis and tube formation of meningioma IOMM-Lee and CH157-MN cells transfected with overexpressed FOXM1 were examined with MTT assay, clone formation assay, flow cytometry and tube formation assay, respectively. The expressions of AHR and cytochrome P450 family 1 subfamily A member 1 (CYP1A1) in meningioma and adjacent tissues were detected using qRT-PCR, and the correlation of AHR with FOXM1 was analyzed with Pearson's correlation analysis. Western blot was conducted for measuring the expressions of vascular endothelial growth factor A (VEGFA), AHR and CYPIA1. The cell viability, proliferation, apoptosis and tube formation capability were further determined after treatment with StemRegenin 1 (SR1) (an AHR signaling pathway inhibitor), and transfected with or without overexpressed FOXM1. Results: FOXM1, AHR and CYP1A1 expressions were upregulated in malignant meningioma tissues. Overexpressed FOXM1 promoted meningioma cell viability, proliferation, tube formation, upregulated expressions of AHR, CYP1A1 and VEGFA, and inhibited the cell apoptosis. AHR was positively correlated with FOXM1. SR1 suppressed meningioma cell growth and the AHR signaling pathway, and also reversed the active effect of FOXM1 on meningioma cells. Conclusions: FOXM1 may promote malignant meningioma via the AHR signaling pathway, which improved the current understanding of the role of FOXM1 in meningioma.
\end{abstract}

Key words: FOXM1, malignant meningioma, tube formation, growth, AHR signaling pathway.

\section{Introduction}

Meningioma, which is a tumor occurring at the tissue layer covering the brain or spinal cord, is one of the most vital and frequent cancers occurring in the central nervous system (CNS), with a high morbidity of $30-40 \%[2,21]$. Meningioma is classified into three different grades by the classification by the World Health

\section{Communicating author}

Songtao Qi, Department of Neurosurgery, Nanfang Hospital, Southern Medical University, No. 1838, North Guangzhou Avenue, Guangzhou, Guangdong Province, 510515, China, phone: 86-020-61641801, e-mail: songtao_qist@163.com 
Organization [29]. Though most meningioma cases in primary qualitative classification are benign tumors, discoveries from clinical researchers showed that malignant meningioma may also occur, with a rapid growth and metastasis [19]. Despite great efforts invested in the development of meningioma diagnosis and treatment, the prognosis of meningioma remained unfavorable due to its high recurrence rate and unknown pathogenesis [33]. Therefore, further investigation into the molecular mechanisms of the onset and progression of meningioma are required, so as to provide possible clinical therapeutic strategies for the cancer.

Forkhead Box M1 (FOXM1), a member of the forkhead gene family, is a transcriptional regulator of the transition from G1/S to G2/M phase and progression on $M$ phase in the cell cycle. FOXM1 plays a pivotal role in several physiological and pathological processes [11,22]. Sheng et al. showed that FOXM1 plays an essential role in survival, quiescence, and self-renewal of MLL-AF9 (MA9)-transformed leukemia stem cells [23]. Hu et al. also addressed that FOXM1 could promote progression of hepatocellular carcinoma (HCC) through regulating the expression of kinesin family member 4A (KIF4A) [6]. Moreover, the study also found out that FOXM1 participated in the resistance of cancer stem cells to taxanes through a signaling pathway mediated by UHRF1 [31]. As for its role in meningioma, FOXM1 has been recognized as an oncogenic driver in the progression of human meningioma [8]. However, so far, there have been only a limited number of studies conducted on the possible molecular mechanisms through which FOXM1 promoted the development and progression of meningioma. Previously, the aryl hydrocarbon receptor (AHR) signaling pathway, which has been found to play a major role in cardiovascular diseases by acting as a signal transmitter of oxidative stress [12], also functions critically in meningioma development [13]. However, its correlation with FOXM1 was poorly discussed.

This study focused on the involvement of FOXM1 in meningioma and its correlation with the AHR signaling pathway, with a hope to develop a better understanding of the role of FOXM1 in meningioma and to bring further insights into meningioma pathogenesis.

\section{Material and methods \\ Ethical statement}

Clinical malignant meningioma tissue samples and normal adjacent tissues were collected from
40 patients diagnosed with meningioma in the Affiliated Hospital of Inner Mongolia Medical University between July 2019 and December 2019. The clinical trial program had been carefully reviewed and was approved by the Ethics Committee of Affiliated Hospital of Inner Mongolia Medical University (approval number: SJWK20190728). Written informed consent was signed by each enrolled patient. Adjacent tissues $1 \mathrm{~cm}$ or more away from the meningioma tissues were collected. All the patients recruited met the following criteria: a) without chemotherapy or radiotherapy received; b) without other cancers, autoimmune or contagious diseases, etc. After the surgical resection, the samples were washed with phosphate-buffered saline (PBS) and well-preserved at $-80^{\circ} \mathrm{C}$.

\section{Cell culture and treatment}

Human meningioma cell line IOMM-Lee (catalog number: CRL-3370) and human malignant meningioma cell line CH157-MN were ordered from American type culture collection (ATCC; Rockville, MD, USA) and Chinese Academy of Medical Sciences (Beijing, China), respectively. The two cell lines were cultured in Dulbecco's modified eagle medium (DMEM; Invitrogen, Carlsbad, CA, USA), which consisted of $10 \%$ fatal bovine serum (FBS; Invitrogen, USA), $100 \mathrm{U} / \mathrm{ml}$ penicillin (Invitrogen, USA) and $100 \mathrm{mg} / \mathrm{ml}$ streptomycin (Invitrogen, USA), in an incubator at $37^{\circ} \mathrm{C}$ with $5 \% \mathrm{CO}_{2}$.

Human umbilical vein endothelial cells (HUVECs; catalog number: PCS-100-010; ATCC, USA) were cultured in endothelial growth medium-2 (ECM; ScienCell, USA) supplemented with 5\% FBS (ScienCell, USA), endothelial cell growth supplement (ECGS; ScienCell, USA), $100 \mathrm{U} / \mathrm{ml}$ penicillin, and $100 \mathrm{U} / \mathrm{ml}$ streptomycin (Invitrogen, USA) in an incubator at $37^{\circ} \mathrm{C}$ with $5 \% \mathrm{CO}_{2}$.

For cell transfection, the meningioma cells $\left(1 \times 10^{6}\right.$ cells/well) were seeded into a 6 -well plate. FOXM1 was successfully overexpressed by the transfection with pcDNA3.1-FOXM1 plasmid. Then, after the cells reached $80-90 \%$ confluency, $2 \mu$ lipofectamine 3000 reagent (Thermo Fisher Scientific, USA) in a mixture with $1 \mu \mathrm{g}$ FOXM1 overexpression or empty plasmids were transfected into the cells, according to the instruction. The meningioma cells were collected $48 \mathrm{~h}$ after the transfection. Then, to examine the relationship between the AHR signaling pathway and FOXM1-transfected meningioma cells, AHR signaling pathway inhibitor StemRegenin 1 (SR1; catalog no. 
S2858; Selleck, Houston, TX, USA) was added into the IOMM-Lee and CH157-MN cells $48 \mathrm{~h}$ after the FOXM1 transfection.

\section{MTT assay}

The IOMM-Lee and CH157-MN cells $\left(2 \times 10^{5}\right.$ cells $\left./ \mathrm{ml}\right)$ seeded into 96-well plates were added with MTT assay kit (10 $\mu$ l; M1210, Solarbio, Beijing, China) for cell culture for 24, 48 and $72 \mathrm{~h}$. The culture supernatant was abandoned after incubation at $37^{\circ} \mathrm{C}$ for $4 \mathrm{~h}$, and $100 \mu$ ldimethyl sulfoxide (DMSO; 472301, SigmaAldrich, USA) was added to the cells to dissolve formazan crystals. OD values were measured and recorded by microplate reader (Model 680, Bio-Rad, USA) at an absorbance of $490 \mathrm{~nm}$.

\section{Clone formation assay}

The meningioma cells $\left(1 \times 10^{2}\right.$ cells/well $)$ were seeded into 96 -well plates at $37^{\circ} \mathrm{C}$ with $5 \% \mathrm{CO}_{2}$ for 2-week cell culture. Then the cells were fixed by pure methanol for $15 \mathrm{~min}$, followed by Giemsa staining at $37^{\circ} \mathrm{C}$ for $30 \mathrm{~min}$. Colonies were observed with an inverted optical microscope (MVX10; Olympus Corporation, Tokyo, Japan). Each colony images were calculated for clone formation number.

\section{Flow cytometry}

Forty eight hours after the transfection, the meningioma cells $\left(1 \times 10^{5}\right)$ were treated with Annexin $\mathrm{V}$ and propidium iodide $(\mathrm{PI})$ together for $15 \mathrm{~min}$ at room temperature in the dark. Cell apoptosis was detected with Annexin V-FITC cell apoptosis kit (APOAF-50TST; Sigma-Aldrich, USA), and the data were analyzed using Kaluza C Analysis Software (Beckman Coulter, Indianapolis, IN, USA).

\section{Tube formation assay}

After culturing the HUVECs for 6-8 h, the cells were then co-cultured with meningioma cells for tube formation in vitro. In detail, the HUVECs $\left(2 \times 10^{4}\right.$ cell/well $)$ co-cultured with the meningioma cells $\left(2 \times 10^{4}\right.$ cell/ well) were plated onto the Matrigel layer (R\&D Systems, Minneapolis, MN, USA) in DMEM medium. Four hours later, the formation of capillary-like structures was captured under an inverted optical microscope (SW380T, Swift Optical Instruments, Schertz, TX, USA) and analyzed by Tube formation ACAS Image Analysis Software (v.1.0, ibidi GmbH, Gräfelfing, Germany).

\section{RNA isolation and quantitative real-time polymerase chain reaction ( $q R T-P C R$ )}

Trizol reagent (Invitrogen, USA) was used to extract total RNA from meningioma tissues and cells following the manufacturer's instructions. The extracted RNA was preserved in $\mathrm{a}-80^{\circ} \mathrm{C}$ refrigerator, and the RNA concentration was later quantified using a biological spectrometer (Nano Drop 2000, Thermo Fisher Scientific, USA). The synthesis of CDNA from of total RNA $(1 \mu \mathrm{g})$ was performed using a PrimeScript $1^{\text {st }}$ strand CDNA Synthesis Kit (6110A; Takara Bio, Beijing, China) based on the manufacturer's instructions. QRT-PCR experiment was conducted with PrimeScript ${ }^{\mathrm{TM}}$ RT Master Mix (Perfect Real Time) kit (RR036Q; TaKaRa Bio, China) in a SmartChip ${ }^{\text {TM }}$ Real-Time PCR System (640022; Takara Bio, China) under the following conditions: at $94^{\circ} \mathrm{C}$ for $2 \mathrm{~min}$, followed by $35 \mathrm{cycles}$ at $94^{\circ} \mathrm{C}$ for $30 \mathrm{~s}$, at $60^{\circ} \mathrm{C}$ for $30 \mathrm{~s}$ and at $72^{\circ} \mathrm{C}$ for $1 \mathrm{~min}$. The primer sequences used were listed in Table I, with glyceraldehyde-3-phosphate dehydrogenase (GAPDH) used as an internal control. $2^{-\triangle \triangle C T}$ calculation method was used for the quantification of relative gene expressions [12].

\section{Western blot}

Western blot for determining the protein expressions of Vascular endothelial growth factor A (VEGFA), AHR and cytochrome P450 family 1 subfamily A member 1 (CYP1A1) were conducted by referring to a previous description [25]. RIPA buffer (R0278; Sigma-Aldrich, USA) was employed for the lysis and extraction of proteins from the meningioma cells. The concentration of the protein was detected by bicin-

Table I. Primers for qRT-PCR

\begin{tabular}{|cc|}
\hline \multicolumn{1}{|l|}{ Gene } & Primers \\
\hline FOXM1 & \\
\hline Forward & 5'-TTGACATTGGACCAGGTGTTT-3' \\
\hline Reverse & 5'-GGAGTTCGGTTTTGATGGTC-3' \\
\hline AHR \\
\hline Forward & 5'-TGCTTCATCTGCCGTGTG-3' \\
\hline Reverse & 5'-TTGAAACTGCATCGTCAGGA-3' \\
\hline CYP1A1 & \\
\hline Forward & 5'-ACCTTCCCTGATCCTTGTGA-3' \\
\hline Reverse & 5'-GATCTTGGAGGTGGCTGCT-3' \\
\hline GAPDH & \\
\hline Forward & 5'-TTTTTGGTTTTAGGGTTAGTTAGTA-3' \\
\hline Reverse & 5'-AAAACCTCCTATAATATCCCTCCTC-3' \\
\hline
\end{tabular}


choninic acid (BCA) protein kit (B9643; Sigma-Aldrich, USA). Sample protein lysates $(30 \mu \mathrm{g})$ were electrophoresed by $10 \%$ sodium dodecyl sulfate-polyacrylamide gel electrophoresis (SDS-PAGE; P0012A; Beyotime, China) and were transferred onto polyvinylidene fluoride (PVDF) membrane (IESQ00010, Solarbio, China). After blocking the membrane with nonfat milk $(5 \%)$ for $2 \mathrm{~h}$, the membrane was incubated within the primary antibodies as follows: anti-VEGFA antibody (ab46154, $1: 1000$, Abcam, Cambridge, UK), anti-AHR antibody (\#83200, $1: 1000$, Cell Signaling Technology, Danvers, MA, USA), anti-CYP1A1 antibody (ab79819, 1 : 100, Abcam, UK) and anti-GAPDH antibody (ab8245, $1: 10000, \mathrm{Abcam}, \mathrm{UK}$ ), at $4^{\circ} \mathrm{C}$ overnight, with GAPDH as an internal control. The membrane was then incubated in secondary horseradish peroxidase (HRP)-combined antibodies (goat anti-rabbit IgG H\&L (HRP) (1 : 2000, A0208, Beyotime, China) and goat anti-mouse IgG H\&L (HRP) (1: 2000, A0216, Beyotime, China)) for $1 \mathrm{~h}$ at room temperature. After the membrane was washed with tris-buffer saline tween (TBST) for three times, we gathered and analyze the protein band with an enhanced chemiluminescence (ECL) kit (PE0010; Solarbio, Beijing, China). The grey values of the strips were further gathered and were calculated using ImageJ (version 5.0; Bio-Rad, USA).

\section{Statistical analysis}

All the experiments were conducted in independent triplicate. The experimental data were expressed as mean \pm standard deviation (SD). Statistical analysis was performed in SPSS 20.0 software (IBM Corporation, Armonk, NY, USA). Significances of the statistics were determined by one-way ANOVA and Student's $t$ test, followed by Dunnett's post hoc test. Correlation analysis between FOXM1 and AHR in the malignant meningioma and adjacent normal tissues was conducted using Pearson's correlation test. A statistical difference was defined when $p<0.05$.

\section{Results}

\section{FOXM1 expression was upregulated in the meningioma tissues}

To uncover the relation between FOXM1 and meningioma, we collected meningioma tissues and their paired adjacent normal tissues ( $n=40$ for each group), and then measured FOXM1 expression by qRT-PCR. The results showed that FOXM1 expression was evidently more upregulated in meningioma tis- sues (Tumor) than that in adjacent normal tissues (Adjacent) (Fig. 1A, $p<0.001$ ), suggesting that FOXM1 may be implicated in meningioma development.

\section{Overexpressed FOXM1 promoted the viability, proliferation and tube formation but inhibited apoptosis of meningioma cells}

After transfection of FOXM1 into meningioma cells IOMM-Lee and malignant meningioma cells CH157-MN, the effects of FOXM1 on the viability, proliferation and apoptosis of the two cells were assessed with MTT assay, clone formation assay and flow cytometry. The viabilities of IOMM-Lee and CH157-MN cells were measured at 24, 48 and $72 \mathrm{~h}$ with MTT assay, as shown in Figure $1 \mathrm{~B}$ and $1 \mathrm{C}$, at 48 and $72 \mathrm{~h}$, the viabilities of IOMM-Lee and CH157$M N$ cells after the transfection with FOXM1 were evidently increased ( $p<0.01$, vs. negative control [NC]), indicating that FOXM1 could promote meningioma cell viability. Clone formation assay was conducted for the measurement of the number of colonies formed by meningioma cells. We observed that on day 14, the number of colonies formed by IOMMLee and CH157-MN cells was increased (Fig. 1B, C, $p<0.001$, vs. NC), and this showed that FOXM1 may promote meningioma cell proliferation.

Subsequently, cells apoptosis of IOMM-Lee and CH157-MN after the transfection with FOXM1 was determined. As presented in Figure $2 \mathrm{~A}$ and $\mathrm{B}$, both IOMM-Lee and CH157-MN cell apoptosis rates were significantly reduced ( $p<0.001$, vs. NC), indicating that FOXM1 could inhibit meningioma cell apoptosis.

Tube formation assay was performed to simulate angiogenesis in vitro for examining the possible effects of FOXM1 on the tube regeneration of HUVECs mediated by meningioma cells. In our experiments, we found that after the FOXM1 transfection, relative tube length of HUVECS mediated by both IOMM-Lee and CH157-MN cells became evidently longer (Fig. 2 C, D, $p<0.001$, vs. NC), indicating that FOXM1 could promote the tube formation of HUVECS mediated by meningioma cells.

\section{AHR signaling pathway was positively correlated with FOXM1 in malignant meningioma}

To verify the relation between the AHR signaling pathway and FOXM1 in meningioma, we measured 
A

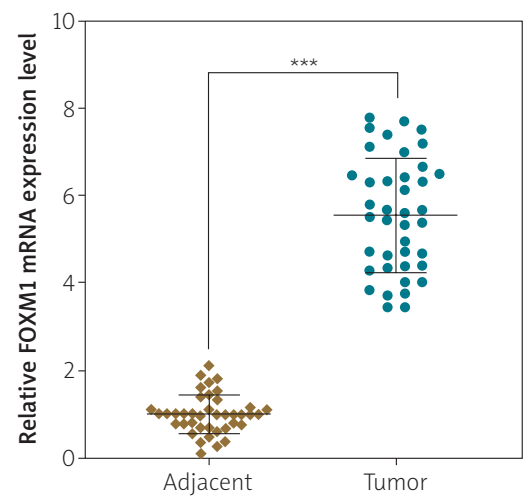

D
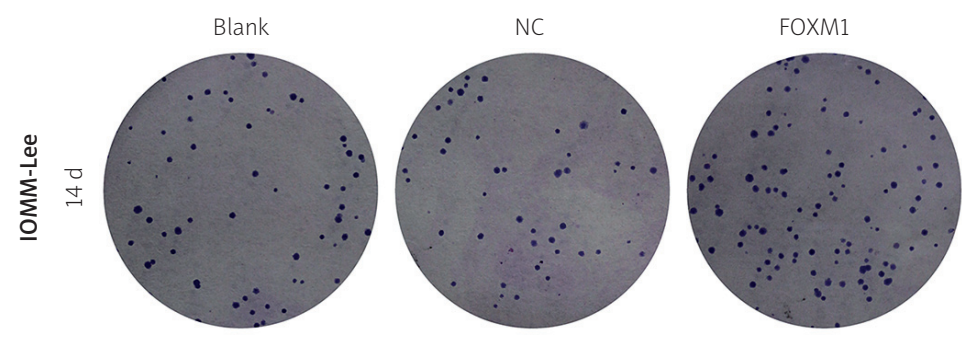

$\mathrm{E}$
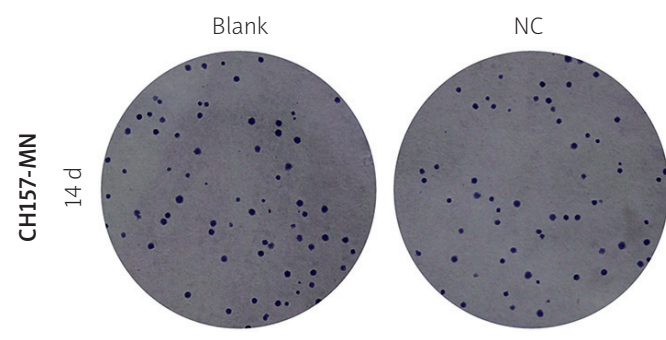

B

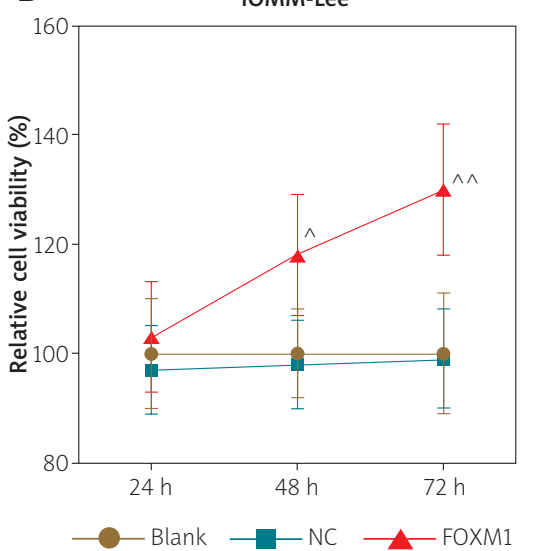

C $\quad$ CH157-MN
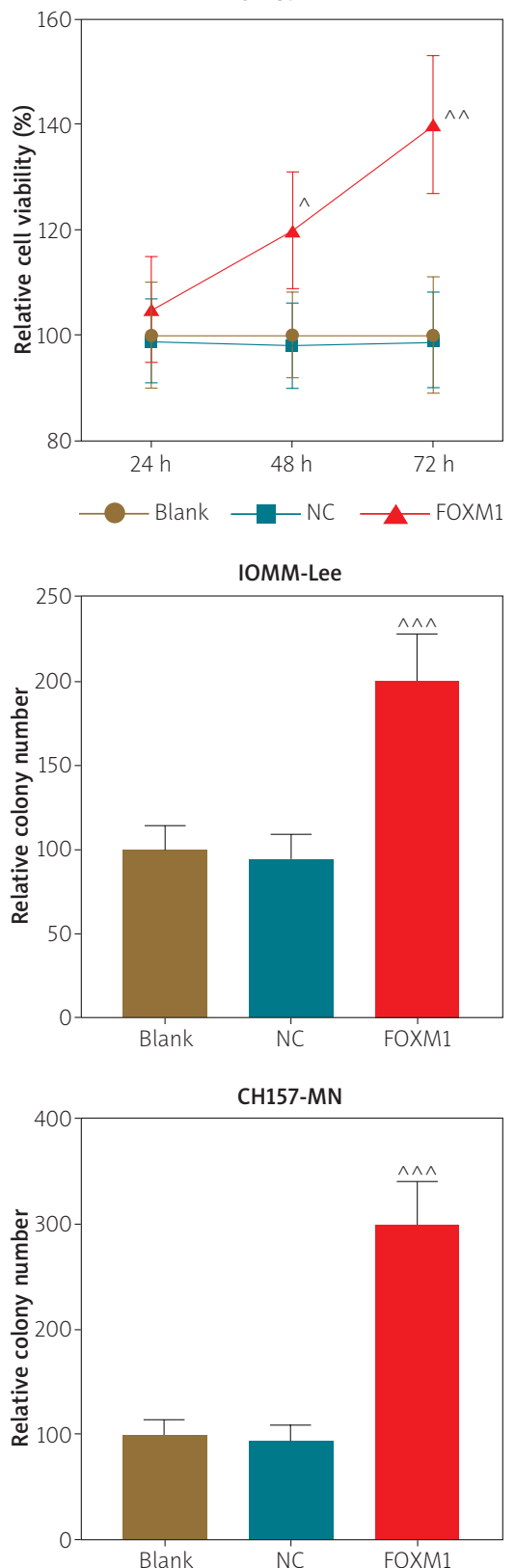

Fig. 1. Forkhead Box M1 (FOXM1) expression was upregulated in meningioma tissues and promoted the viability and proliferation of meningioma cells. A) Relative FOXM1 expressions in meningioma tissues (Tumor) and paired adjacent normal tissues (Adjacent) were measured with quantitative real-time polymerase chain reaction (qRT-PCR). GAPDH was used as an internal control ( $n=40$ for each group). B, C) The viabilities of meningioma cells IOMM-Lee (B) and CH157-MN (C) at 24, 48 and $72 \mathrm{~h}$ were measured with MTT assay. D, E) The proliferation of meningioma cells IOMM-Lee (D) and CH157-MN (E) on day 14 was measured with clone formation assay. All the experiments were performed in triplicate and the experimental data were expressed as mean \pm standard deviation (SD). ${ }^{* * *} p<0.001$, vs. Adjacent; ${ }^{\wedge} p<0.05,{ }^{\wedge} p p<0.01$, $\wedge \wedge \wedge p<0.001$, vs. NC. NC - negative control. 
expressions of proteins related to the AHR signaling pathway (AHR and CYP1A1) in malignant meningioma and adjacent normal tissues by qRT-PCR $(n=40$ for each group). In Figure $3 A$ and $B$, both $A H R$ and CYP1A1 expressions in malignant meningioma tissues were upregulated ( $p<0.001$, vs. Adjacent), suggesting that the AHR signaling pathway may be implicated in meningioma development. Furthermore, as shown in Figure $3 C$ and $D$, a positive correlation between FOXM1 and AHR expression could be identified in both normal adjacent tissues (Fig. 3C, $r=0.453, p=0.003$ ) and meningioma tissues (Fig. 3D, $r=0.457, p=0.001)$. These data therefore suggested that the AHR signaling pathway may be regulated by FOXM1.

\section{FOXM1 upregulated the expressions of VEGFA and proteins related to the AHR signaling pathway in meningioma cells}

As VEGFA is a key factor in vascular growth [24], then, in order to confirm that FOXM1 could regulate VEGFA expression and the AHR signaling pathway in the meningioma cells, we also measured the expression of VEGFA and proteins related to the AHR signaling pathway (AHR, CYP1A1) by performing Western blot. After upregulating FOXM1 expression in both IOMM-Lee and CH157-MN cells, an increased expression of VEGFA and proteins related to the AHR signaling pathway (AHR, CYP1A1) were detected, as compared with the NC group (Fig. 3E, F, $p<0.001$ ). Therefore, it could be concluded that FOXM1 could upregulate the expressions of VEGFA and proteins related to the AHR signaling pathway in the meningioma cells.

\section{SR1 reversed the effects of FOXM1 on the viability, proliferation, apoptosis and tube formation of meningioma cells}

In order to determine whether the AHR signaling pathway played a vital role in FOXM1-mediated meningioma cell viability, proliferation and apoptosis, we treated IOMM-Lee and CH157-MN cells with the AHR signaling pathway inhibitor StemRegenin 1 after the transfection of FOXM1. As shown in Figure $4 \mathrm{~A}$ and $\mathrm{B}$, the MTT assay demonstrated that FOXM1 transfection increased the cell viabilities of IOMM-Lee and CH157-MN at 48 and 72 h ( $p<0.01$, vs. NC). However, the cell viabilities at 48 and $72 \mathrm{~h}$ dropped after the treatment with SR1 $(p<0.01$, vs. NC). Furthermore, SR1 treatment reversed the effects of FOXM1 on IOMM-Lee and CH157-MN cell viabilities $(p<0.01)$. Next, the effects of SR1 on FOXM1-mediated meningioma cell proliferation were examined with clone formation assay. As shown in Figure 4C and D, after the IOMM-Lee and CH157-MN cells were transfected with FOXM1, an increased number of colonies formed was observed ( $p<0.001$, vs. NC), whereas SR1 treatment reduced the colony formation $(p<0.001)$. Moreover, SR1 treatment reversed the effects of FOXM1 on the number of colonies formed by IOMM-Lee and CH157-MN cells ( $p$ < 0.001). In brief, FOXM1 could promote viability and proliferation of meningioma cells via the AHR signaling pathway.

In Figure $5 \mathrm{~A}$ and $\mathrm{B}$, decreases of the cell apoptosis of IOMM-Lee and CH157-MN cells transfected with FOXM1 could be found ( $p<0.001$ ). However, after the SR1 treatment, a different result was found ( $p<0.001$ ). In addition, SR1 treatment also reversed the effects of FOXM1 on the meningioma cell apoptosis $(p<0.001)$, showing that FOXM1 could suppress meningioma cell apoptosis via the AHR signaling pathway.

As displayed in Figure $5 C$ and $D$, relative tube lengths of HUVECS co-cultured with both IOMM-Lee and $\mathrm{CH} 157-\mathrm{MN}$ cells were increased after the FOXM1 transfection $(p<0.001)$, while SR1 treatment resulted in an opposite effect $(p<0.001)$. Moreover, SR1 treatment could partially reverse the effects of FOXM1 on relative tube lengths ( $p<0.001$ ), which therefore suggested that FOXM1 could promote meningioma cells-mediated tube formation of HUVEC via the AHR signaling pathway.

\section{FOXM1 upregulated the expressions of VEGF and proteins related to the AHR signaling pathway in meningioma cells}

As shown in Figure $6 \mathrm{~A}$ and $\mathrm{B}$, after IOMM-Lee and CH157-MN cells were transfected with FOXM1, both the expressions of VEGFA and proteins related to the AHR signaling pathway were upregulated $(p<0.001$, vs. NC), but SR1 treatment resulted in an opposite effect $(p<0.001)$. In addition, SR1 treatment partially reversed the effects of FOXM1 on the expressions of VEGFA and proteins related to the AHR signaling pathway $(p<0.001)$, which therefore showed that SR1 could reverse the effects of FOXM1 on the AHR signaling pathway in meningioma cells. 

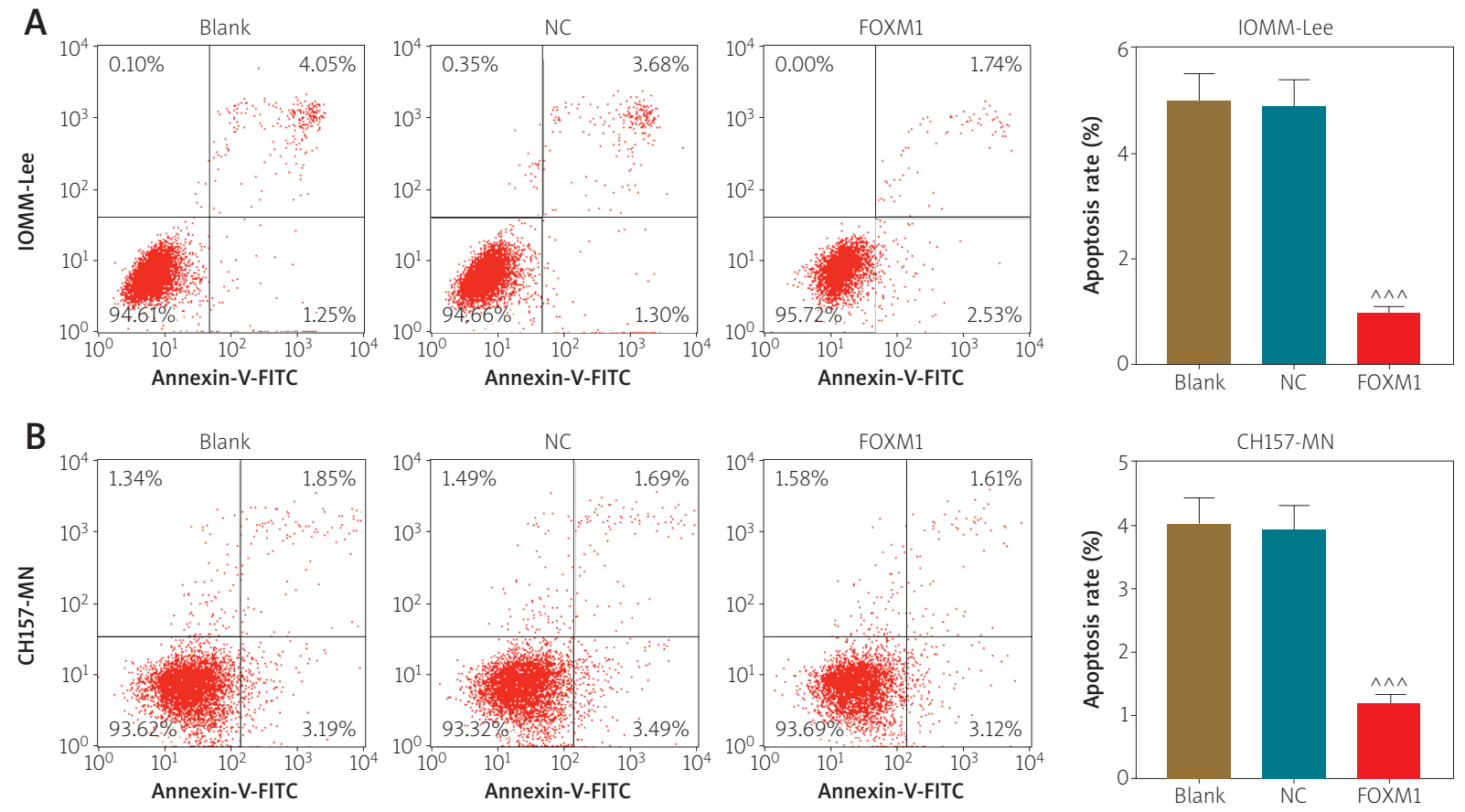

C

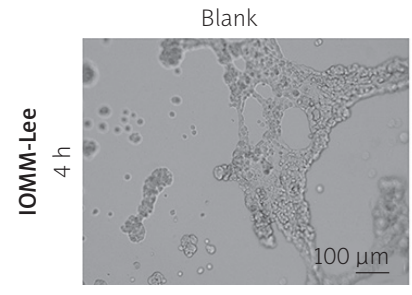

D

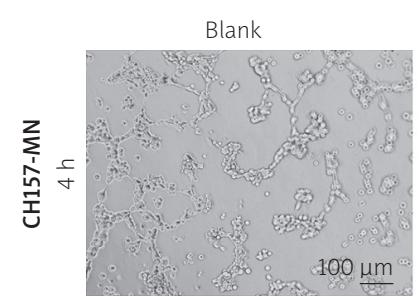

NC

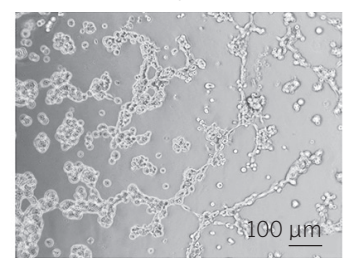

NC
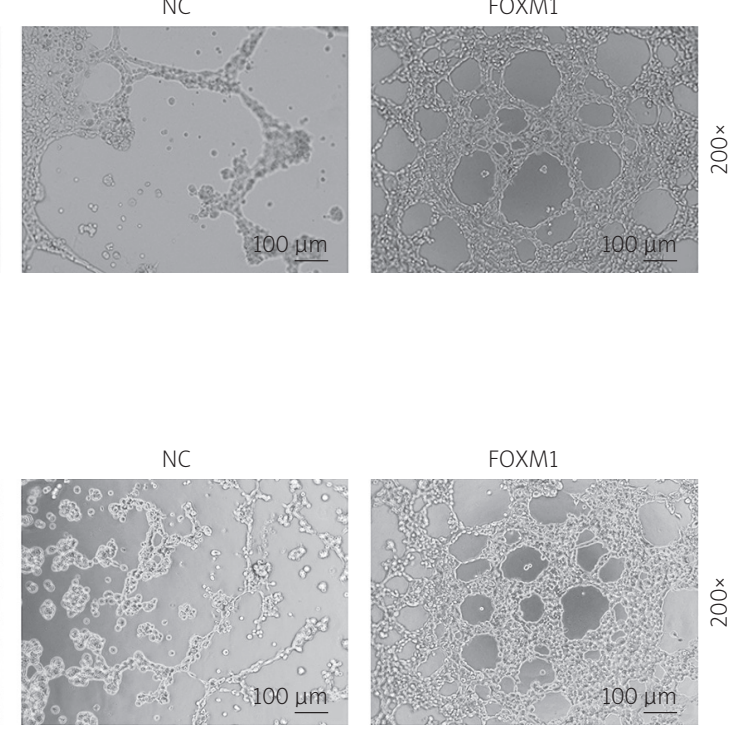
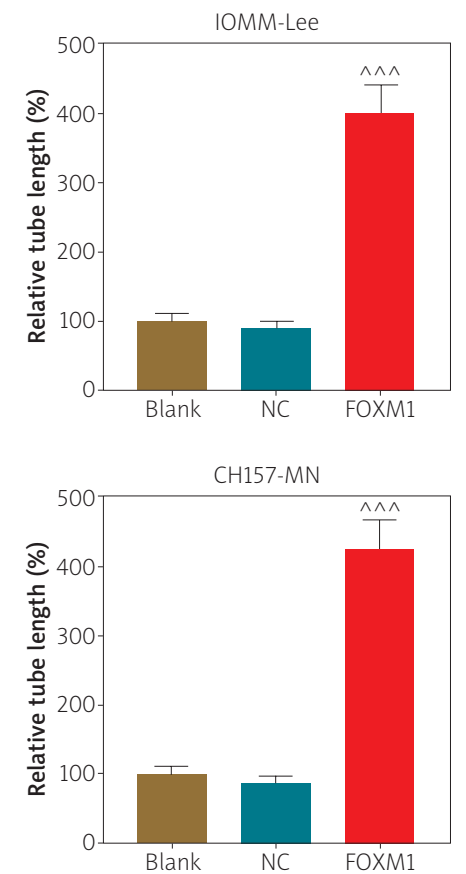

Fig. 2. FOXM1 promoted tube formation and inhibited apoptosis of meningioma cells. A, B) The apoptosis of meningioma cells IOMM-Lee (A) and CH157-MN (B) was measured with flow cytometry. C, D) Relative tube length of HUVECs co-cultured with meningioma cells IOMM-Lee (C) and CH157-MN (D) for $4 \mathrm{~h}$ was assessed by tube formation assay and Matrigel plug assay, under 200x magnification. All the experiments were performed in triplicate and the experimental data were expressed as mean \pm standard deviation (SD). $\wedge \wedge \wedge p<0.001$, vs. NC. HUVECs - human umbilical vein endothelial cells, NC - negative control. 
A

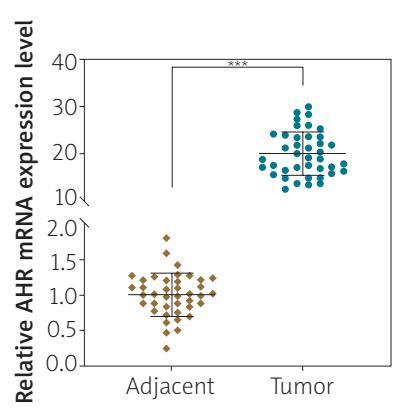

E

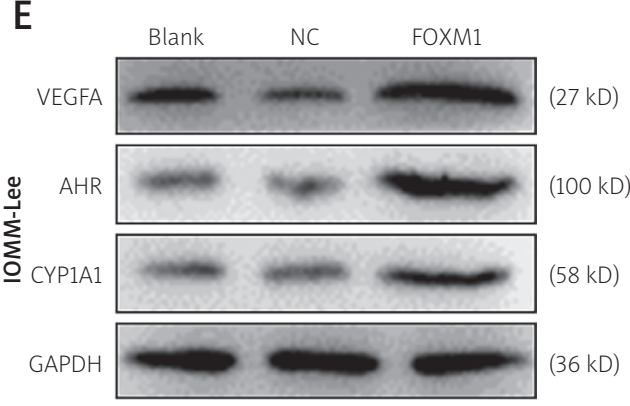

$\mathrm{F}$

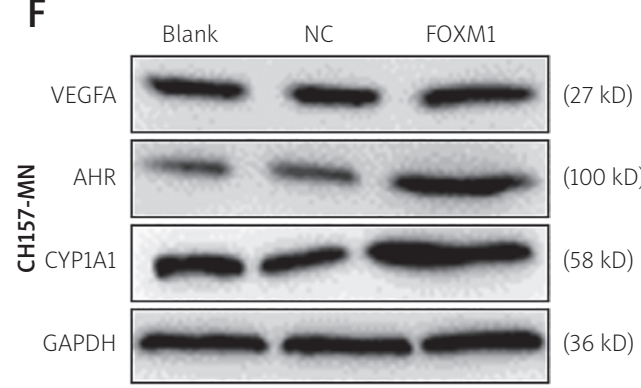

B

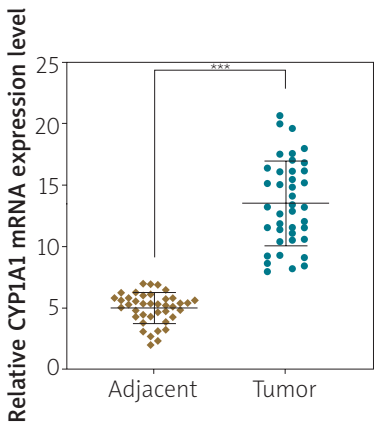

C

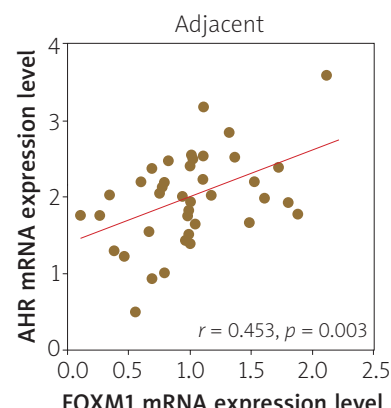

D

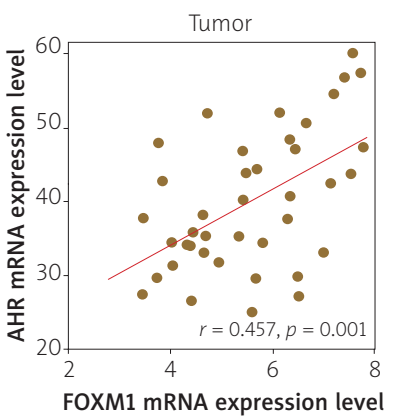

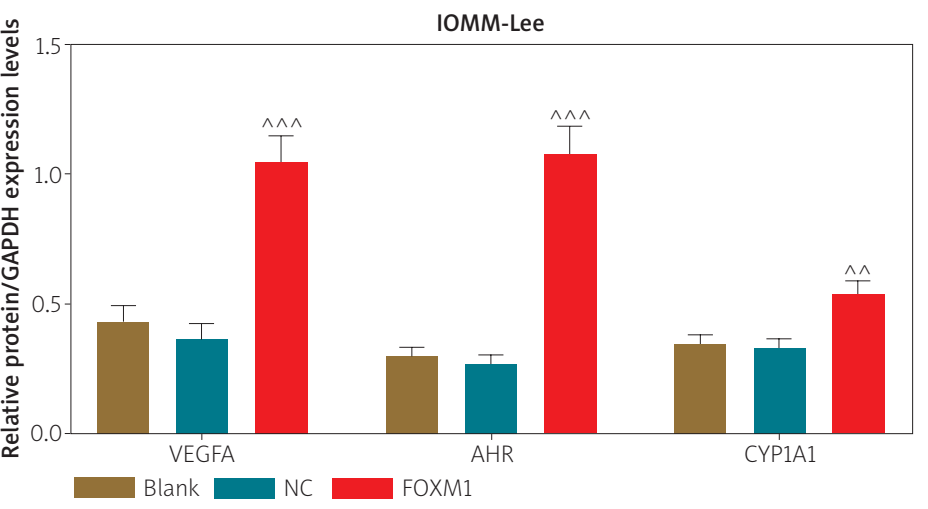

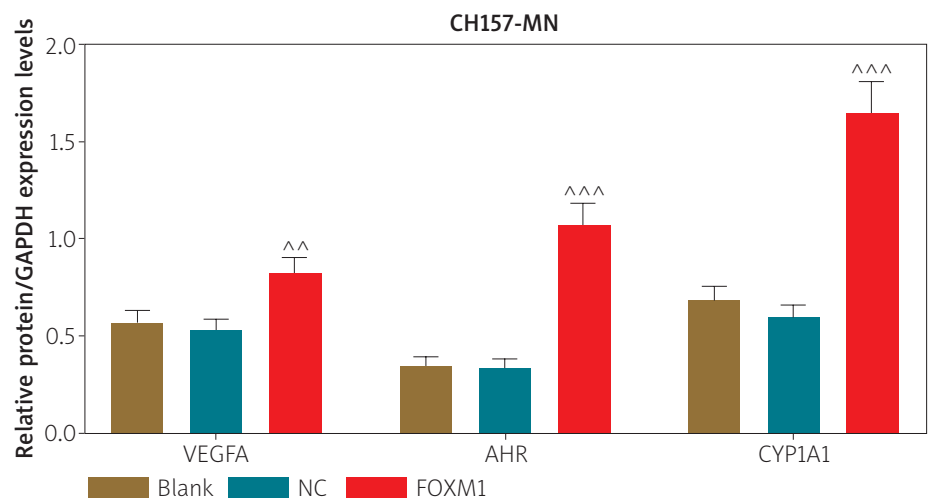

Fig. 3. The expressions of protein related to the AHR signaling pathway and VEGFA regulated by FOXM1. A, B) Relative AHR (A) and CYP1A1 (B) mRNA expressions in meningioma tissues (Tumor) and paired adjacent normal tissues (Adjacent) were measured with qRT-PCR. GAPDH was used as an internal control ( $n=40$ for each group). C, D) Positive correlation between FOXM1 and AHR was shown in adjacent normal (Adjacent) tissues and meningioma tissues (Tumor) tissues. E, F) Relative expressions of VEGFA, AHR and CYP1A1 in meningioma cells IOMM-Lee (E) and CH157-MN (F) were measured with Western blot. GAPDH was used as an internal control. ${ }^{* *} p<0.001$, vs. Adjacent, ${ }^{\wedge} \wedge p<0.01,{ }^{\wedge} \wedge \wedge p<0.001$, vs. NC. All the experiments were performed in triplicate and the experimental data were expressed as mean \pm standard deviation (SD). AHR - aryl hydrocarbon receptor, VEGFA - vascular endothelial growth factor A, CYP1A1 - cytochrome P450 family 1 subfamily A member $1, \mathrm{NC}$ - negative control. 
A

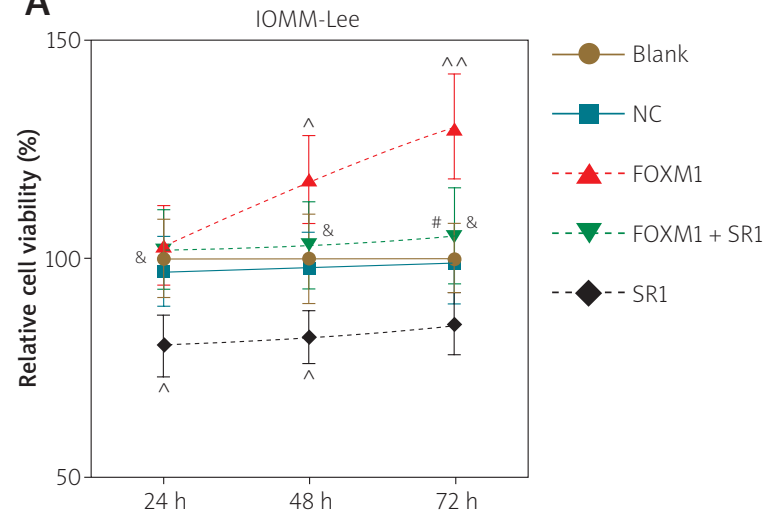

B

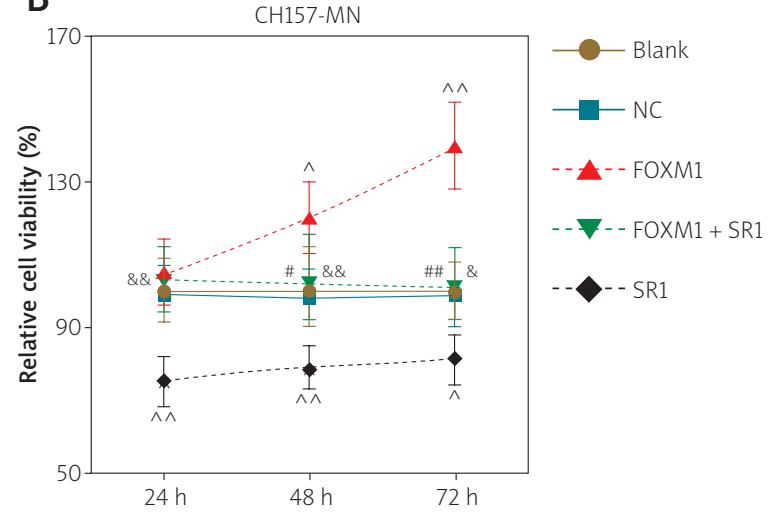

C

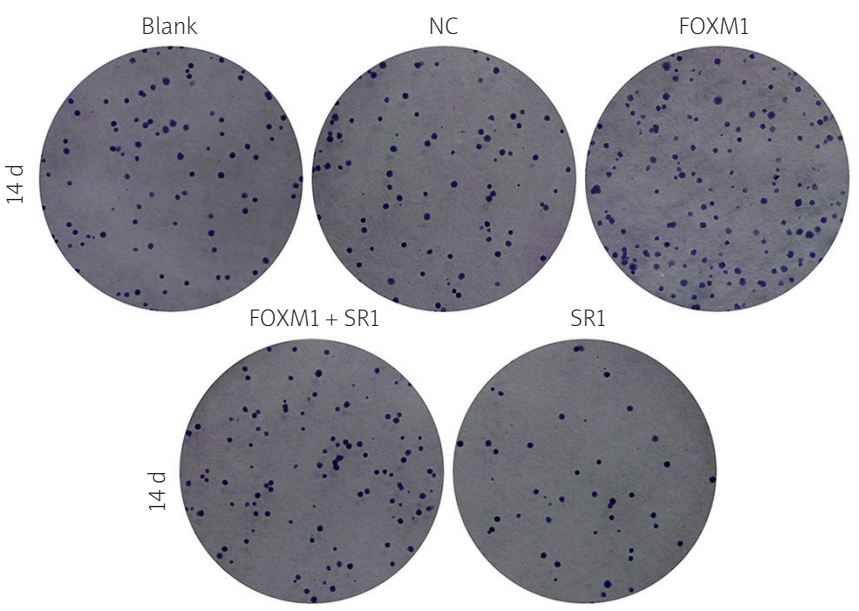

\section{D}

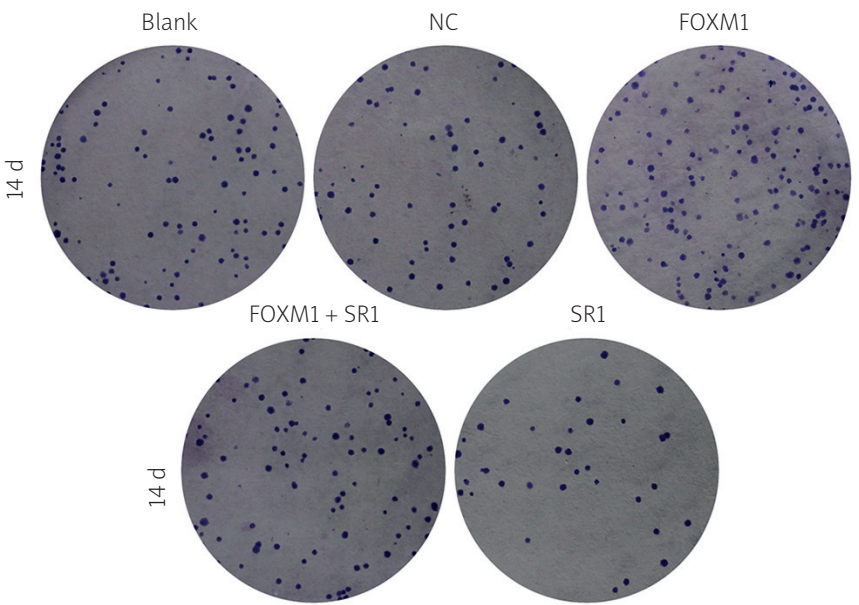

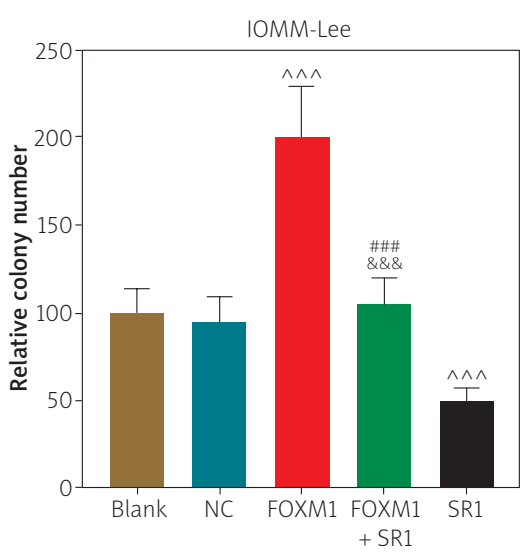

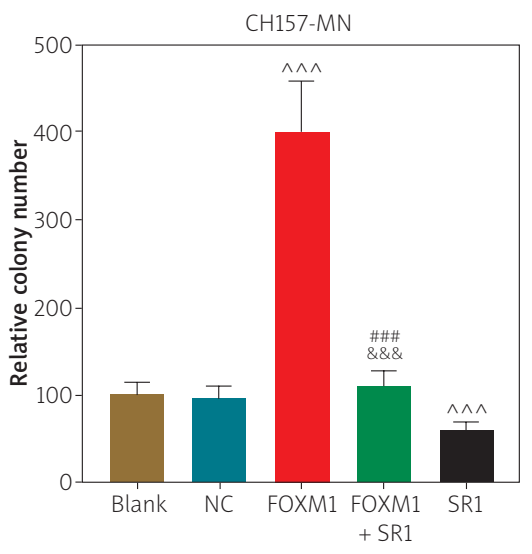

Fig. 4. SR1 reversed the effects of FOXM1 overexpression on promoting the viability and proliferation of meningioma cells. A, B) Relative viabilities of FOXM1-mediated meningioma cells IOMM-Lee (A) and CH157-MN (B) with or without SR1 treatment at 24, 48 and $72 \mathrm{~h}$ were measured with MTT assay. C, D) Relative proliferation of FOXM1-mediated meningioma cells IOMM-Lee (C) and CH157-MN (D) with or without SR1 on day 14 was measured with clone formation assay. All the experiments were performed in triplicate and the experimental data were expressed as mean \pm standard deviation (SD). $\wedge p<0.05, \wedge \wedge p<0.01, \wedge \wedge \wedge p<0.001$, vs. NC, $\&_{p}<0.05, \& \& p<0.01, \& \& \& p<0.001$, vs. SR1, ${ }^{*} p<0.05, \# \#<0.01$, \#\#\# $<0.01$, vs. FOXM1. SR1 - StemRegenin 1 , AHR (aryl hydrocarbon receptor) signaling pathway inhibitor, NC - negative control. 
A
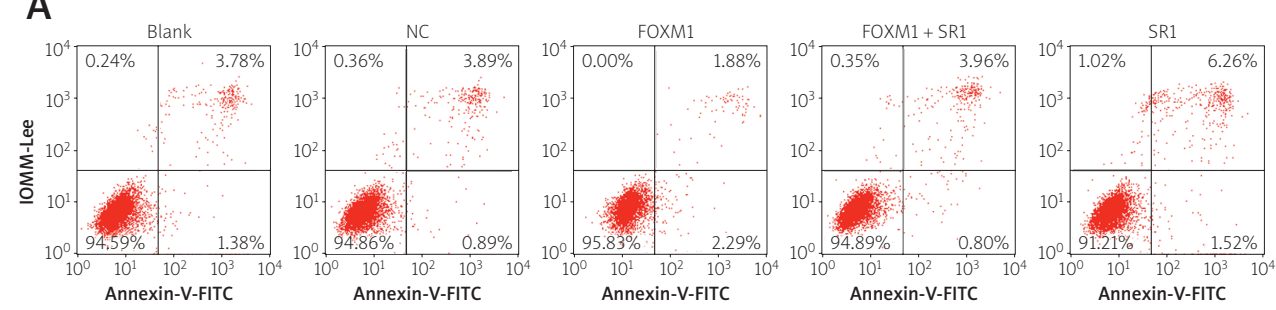

Annexin-V-FITC

B
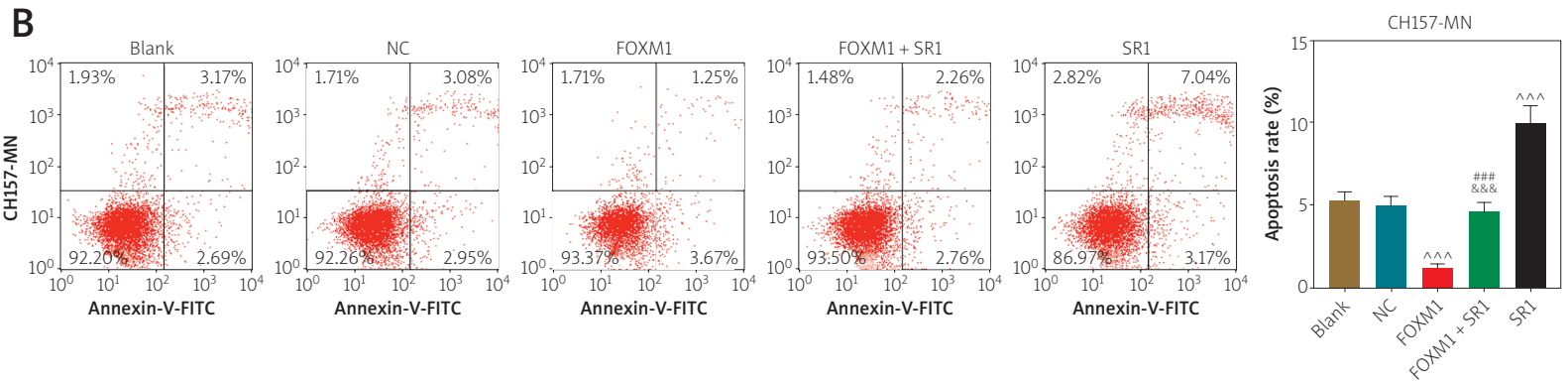

C
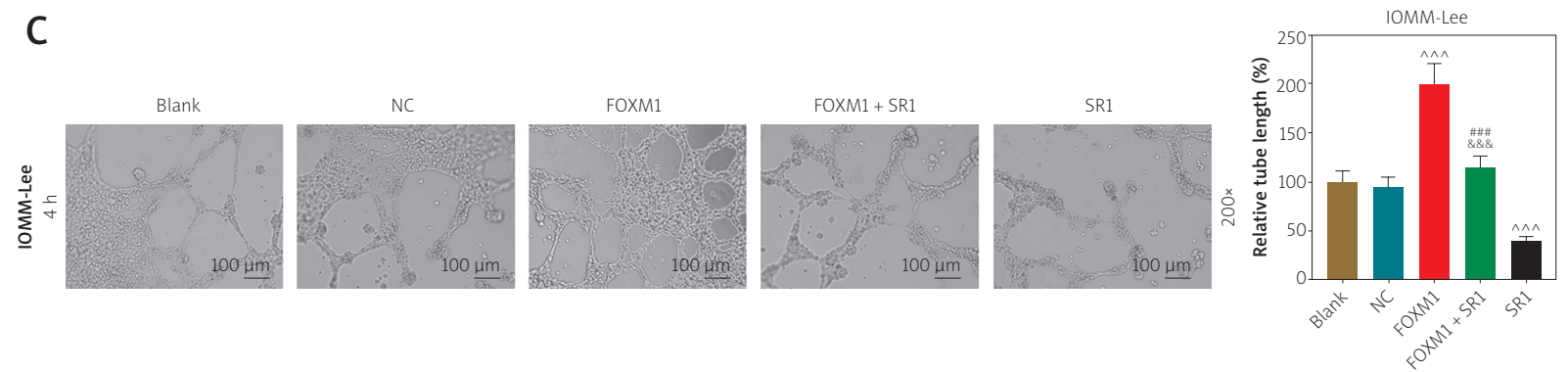

D
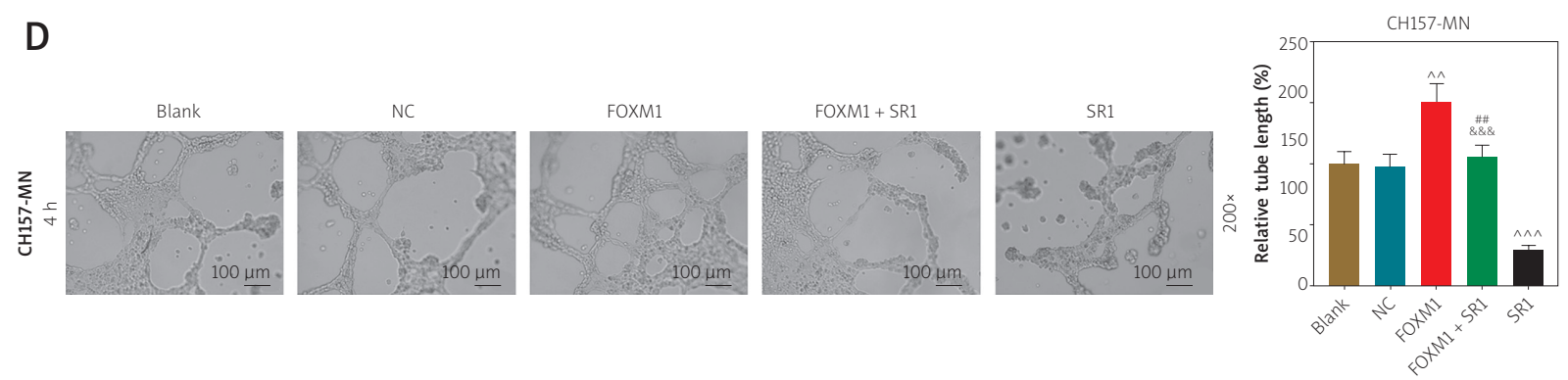

Fig. 5. SR1 reversed the effects of FOXM1 on the apoptosis and tube formation of meningioma cells. A, B) Relative apoptosis of FOXM1-mediated IOMM-Lee (A) and CH157-MN (B) with or without SR1 was measured with flow cytometry. C, D) Relative tube length of HUVECs co-cultured with meningioma cells IOMM-Lee (C) and CH157-MN (D) for $4 \mathrm{~h}$ with or without SR1 was measured with tube formation assay and Matrigel plug assay, under $200 \times$ magnification. $\wedge^{\wedge} p<0.01, \wedge^{\wedge \wedge} p<0.001$, vs. NC, \&\&p $<0.01$, \&\&\&p<0.001, vs. SR1, $\# \#<0.01, \# \# p<0.001$, vs. FOXM1. SR1 - StemRegenin 1, NC - negative control.

\section{Discussion}

Approximately $20 \%$ of meningioma cases are of high grade, relating to a less favorable clinical outcome compared with benign cases [13,28]. Molecular mechanisms underlying meningioma development and progression remained poorly understood. A previous study suggested that in comparison with lowgrade cases, FOXM1 is implicated in the development and progression of high-grade meningioma, with an evidently upregulated mRNA expression of FOXM1 [10]. Also, it has been addressed that poor local recur- 
A

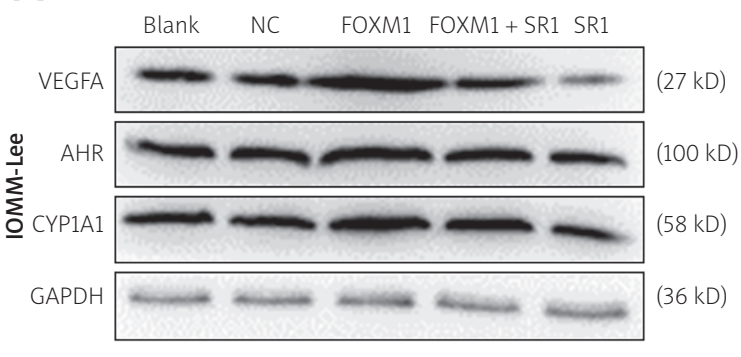

B

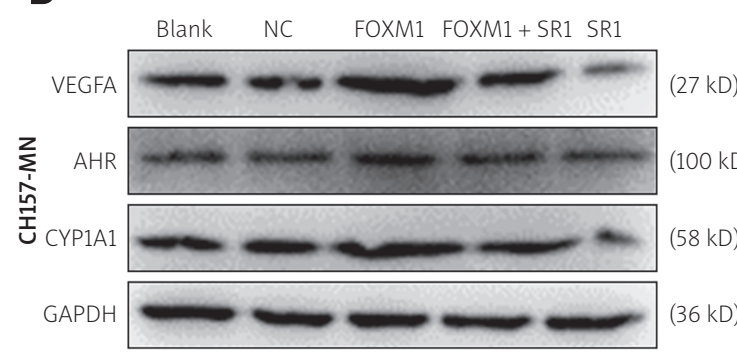

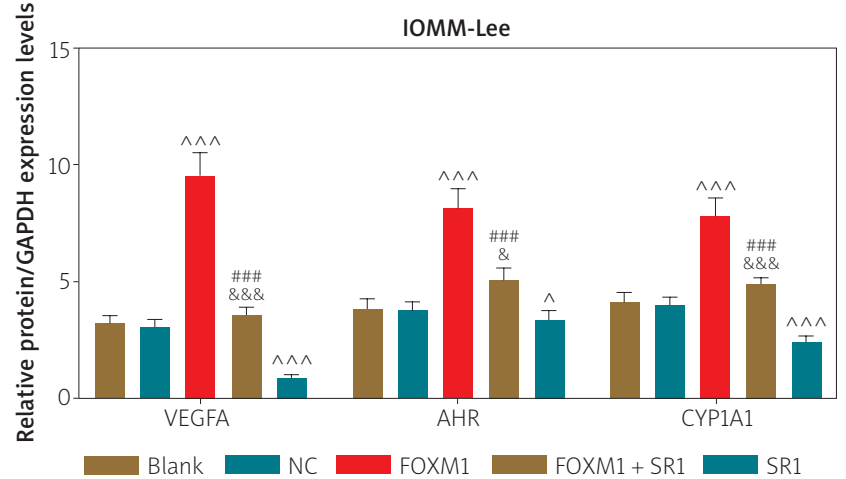

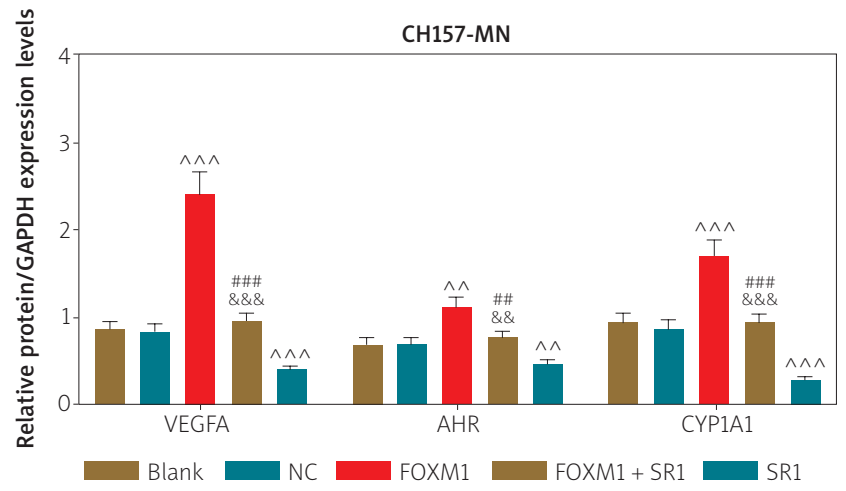

Fig. 6. SR1 reversed the effects of FOXM1 overexpression on the expressions of VEGF and proteins related to the AHR signaling pathway in meningioma cells. A, B) Relative expressions of VEGFA, AHR and CYP1A1 in FOXM1-mediated meningioma cells IOMM-Lee (A) and CH157-MN (B) with or without SR1 were measured with Western blot. GAPDH was used as an internal control. All the experiments were performed in triplicate and the experimental data were expressed as mean \pm standard deviation (SD). $\wedge p<0.05, \wedge \wedge p<0.01$,

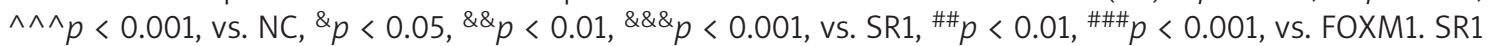
- StemRegenin 1, NC - negative control.

rence-free survival of meningioma patients may be related to the upregulated FOXM1 expression [26]. In addition, in an integrated genomic study, the transcriptional networks of E2F2 and FOXM1 rather than the mutations of TERT promoter have been found involved in atypical meningiomas, as compared with the benign tumors [5]. In the present study, we also measured FOXM1 expression in the meningioma tissues and adjacent normal tissues, and found that FOXM1 expression was upregulated in meningioma tissues as compared with normal adjacent tissues. These discoveries suggested that FOXM1 could be a biomarker and a therapeutic target for malignant meningioma, thus, the detection of FOXM1 expression may contribute to the early diagnosis or prognosis of malignant meningioma. Such a finding provides a new research direction for the pathogenesis and treatment of meningioma.
FOXM1, a transcriptional factor, could regulate certain cellular phenotypes pivotal to tumor progression [9]. Moreover, FOXM1 has also been found as a regulator of both cell cycle and the progression of various cancers $[3,18]$. Thus, the role of FOXM1 in meningioma was studied by examining the effects of upregulating FOXM1 expression on the viability, proliferation, tube formation and apoptosis of meningioma cells. After FOXM1 upregulation, we observed that the viability, proliferation and tube formation of the meningioma cells were evidently increased but the cell apoptosis was decreased. However, the molecular mechanisms of upregulation FOXM1 promoting meningioma development and progression remained to be further uncovered.

Angiogenesis is one of the most pivotal mechanisms through which tumor growth and metastasis are promoted and sustained [7]. Vascular endothe- 
lial growth factors (VEGFs) could promote angiogenesis of meningioma [17]. Some studies also found that FOXM1 could affect the expression of VEGFs. As confirmed by Yang et al., downregulating FOXM1 expression could inhibit VEGF expression, which further inhibits the cell growth and metastasis of bladder cancer cells [30]. Moreover, knocking down FOXM1 may be related to downregulated expression of VEGF-A in colorectal cancer [32]. It has also been found that overexpressed FOXM1 resulted in an upregulation of VEGF [15]. As for the correlation between FOXM1 and VEGF in meningioma, knocking down FOXM1 was observed to suppress VEGFA expression [8]. In our present study, upregulated FOXM1 expression was accompanied by upregulated VEGFA, suggesting that upregulating FOXM1 could promote angiogenesis of meningioma cells.

AHR, a ligand-activated transcription factor, has been found to have a facilitating effect on tumorigenesis with major influences on tumorigenesis, including on initiation, progression and metastasis $[16,20]$. Previous studies showed that reduced AHR signaling could target leukemic stem cells (LSCS), which could be therefore adopted as a method for treating acute myeloid leukemia (AML) [14]. The AHR signaling pathway also exerts effects on the proliferation, development, self-renewal and chemo-resistance of breast cancer stem cells (CSCs) via suppressing PTEN and $\beta$-catenin expressions and Akt activation [1]. In addition, the AHR signaling pathway has been discovered as a novel pathway, which could regulate proliferation of malignant progenitor, of chronic myeloid leukemia [4]. As for the biological function of the AHR signaling pathway in meningioma, Talari et al. demonstrated that upregulated expressions of the main components of AHR signaling pathways were positively related to a higher tumor grade, which therefore provided evidence of the involvement of the AHR signaling pathway in meningioma [25]. However, the correlation between the AHR signaling pathway and FOXM1 has long been poorly understood. In our present study, we found that AHR and CYP1A1 expressions were upregulated in malignant meningioma tissues, and further correlation analysis also showed that AHR was positively correlated with FOXM1. In order to verify the results of the correlation analysis, we measured the expressions of proteins related to the AHR signaling pathway after the upregulation of FOXM1 expression. Our results found a positive correlation between AHR, CYP1A1 and FOXM1 both in malignant meningioma and adjacent normal tissues, suggesting that the AHR signaling pathway could be positively mediated by FOXM1. Previous clinical studies found that SR1 as the AHR signaling pathway inhibitor could increase the expressions of hematopoietic stem and progenitor cells [27]. In our study, after suppressing the AHR signaling pathway by treating the meningioma cells using SR1, the effects of FOXM1 on promoting meningioma cell viability, proliferation, tube formation and on suppressing the apoptosis were reversed, suggesting that FOXM1 could promote the development and progression of meningioma via regulating the AHR signaling pathway.

This study discovered the molecular mechanisms through which FOXM1 promoted the development and progression of malignant meningioma in vitro, but the findings remained to be verified in animals. Thus, the effects of FOXM1 knockdown and overexpression on meningioma tumor growth should be investigated by establishing a tumor model in mice in vivo to further verify our results. Moreover, the regulation of FOXM1 on the AHR signaling pathway was unclear.

In conclusion, we first discovered that FOXM1 could promote the development and progression of malignant meningioma via regulating the AHR signaling pathway. Upregulating FOXM1 expression promoted the viability, proliferation and tube formation of meningioma cells and inhibited the cell apoptosis. At the same time, the expressions of proteins related to angiogenesis and the AHR signaling pathway were upregulated, but the AHR signaling pathway was suppressed. The current findings of the correlation between FOXM1 and the AHR signaling pathway bring further insights into the molecular mechanisms underlying meningioma development and progression.

\section{Disclosure}

The authors declare no conflict of interest.

\section{References}

1. Al-Dhfyan A, Alhoshani A, Korashy HM. Aryl hydrocarbon receptor/cytochrome P450 1A1 pathway mediates breast cancer stem cells expansion through PTEN inhibition and beta-Catenin and Akt activation. Mol Cancer 2017; 16: 14.

2. Apra C, Peyre M, Kalamarides M. Current treatment options for meningioma. Expert Rev Neurother 2018; 18: 241-249. 
3. Feng Y, Li S, Zhang R, Liu F, Xu Q, Ding H, Teng Y. FOXM1 as a prognostic biomarker promotes endometrial cancer progres sion via transactivation of SLC27A2 expression. Int J Clin Exp Pathol 2018; 11: 3846-3857.

4. Gentil M, Hugues P, Desterke C, Telliam G, Sloma I, Souza LEB, Baykal S, Artus J, Griscelli F, Guerci A, Johnson-Ansah H, Foudi A, Bennaceur-Griscelli A, Turhan AG. Aryl hydrocarbon receptor (AHR) is a novel druggable pathway controlling malignant progenitor proliferation in chronic myeloid leukemia (CML). PLoS One 2018; 13: e0200923.

5. Harmanci AS, Youngblood MW, Clark VE, Coskun S, Henegariu O, Duran D, Erson-Omay EZ, Kaulen LD, Lee TI, Abraham BJ, Simon M, Krischek B, Timmer M, Goldbrunner R, Omay SB, Baranoski J, Baran B, Carrion-Grant G, Bai H, Mishra-Gorur K, Schramm J, Moliterno J, Vortmeyer AO, Bilguvar K, Yasuno K, Young RA, Gunel M. Integrated genomic analyses of de novo pathways underlying atypical meningiomas. Nat Commun 2017; 8: 14433.

6. Hu G, Yan Z, Zhang C, Cheng M, Yan Y, Wang Y, Deng L, Lu Q, Luo S. FOXM1 promotes hepatocellular carcinoma progression by regulating KIF4A expression. J Exp Clin Cancer Res 2019; 38: 188.

7. Kargiotis O, Chetty C, Gogineni V, Gondi CS, Pulukuri SM, Kyritsis AP, Gujrati M, Klopfenstein JD, Dinh DH, Rao JS. UPA/UPAR downregulation inhibits radiation-induced migration, invasion and angiogenesis in IOMM-Lee meningioma cells and decreas es tumor growth in vivo. Int I Oncol 2008; 33: 937-947.

8. Kim H, Park KJ, Ryu BK, Park DH, Kong DS, Chong K, Chae YS, Chung YG, Park SI, Kang SH. Forkhead box M1 (FOXM1) transcription factor is a key oncogenic driver of aggressive human meningioma progression. Neuropathol Appl Neurobiol 2020; 46: 125-141.

9. Laoukili J, Stahl M, Medema RH. FoxM1: at the crossroads of ageing and cancer. Biochim Biophys Acta 2007; 1775: 92-102.

10. Laurendeau I, Ferrer M, Garrido D, D'Haene N, Ciavarelli P, Basso A, Vidaud M, Bieche I, Salmon I, Szijan I. Gene expression profiling of the hedgehog signaling pathway in human meningiomas. Mol Med 2010; 16: 262-270.

11. Li Y, Wu F, Tan Q, Guo M, Ma P, Wang X, Zhang S, Xu J, Luo P, Jin $Y$. The multifaceted roles of FOXM1 in pulmonary disease. Cell Commun Signal 2019; 17: 35.

12. Livak KJ, Schmittgen TD. Analysis of relative gene expression data using real-time quantitative PCR and the 2(-Delta Delta C(T)) Method. Methods 2001; 25: 402-408.

13. Louis DN, Perry A, Reifenberger G, von Deimling A, FigarellaBranger D, Cavenee WK, Ohgaki H, Wiestler OD, Kleihues P, Ellison DW. The 2016 World Health Organization classification of tumors of the central nervous system: a summary. Acta Neuropathol 2016; 131: 803-820.

14. Ly M, Rentas S, Vujovic A, Wong N, Moreira S, Xu J, Holzapfel N, Bhatia S, Tran D, Minden MD, Draper JS, Hope KJ. Diminished AHR signaling drives human acute myeloid leukemia stem cell maintenance. Cancer Res 2019; 79: 5799-5811.

15. Monteiro LJ, Cubillos S, Sanchez M, Acuña-Gallardo S, Venegas P, Herrera V, Lam EWF, Varas-Godoy M, Illanes SE. Reduced FOXM1 expression limits trophoblast migration and angiogenesis and is associated with preeclampsia. Reprod Sci 2019; 26: 580-590.
16. Murray IA, Patterson AD, Perdew GH. Aryl hydrocarbon receptor ligands in cancer: friend and foe. Nat Rev Cancer 2014; 14: 801-814.

17. Nassehi D, Sørensen LP, Dyrbye H, Thomsen C, Juhler M, Laursen H, Broholm H. Peritumoral brain edema in angiomatous supratentorial meningiomas: an investigation of the vascular endothelial growth factor A pathway. APMIS 2013; 121: 1025-1036.

18. Nicolau-Neto P, Palumbo A, De Martino M, Esposito F, de Almeida Simao T, Fusco A, Nasciutti LE, Meireles Da Costa N, Ribeiro Pinto LF. UBE2C is a transcriptional target of the cell cycle regulator FOXM1. Genes (Basel) 2018; 9: 188.

19. Ohla V, Scheiwe C. Meningiomatosis restricted to the left cerebral hemisphere with acute clinical deterioration: Case presentation and discussion of treatment options. Surg Neurol Int 2015; 6: 64.

20. Pocar P, Fischer B, Klonisch T, Hombach-Klonisch S. Molecular interactions of the aryl hydrocarbon receptor and its biological and toxicological relevance for reproduction. Reproduction 2005; 129: 379-389.

21. Preusser M, Brastianos PK, Mawrin C. Advances in meningioma genetics: novel therapeutic opportunities. Nat Rev Neurol 2018; 14: 106-115.

22. Rinaldetti S, Wirtz R, Worst TS, Hartmann A, Breyer J, Dyrskjot L, Erben P. FOXM1 predicts disease progression in non-muscle invasive bladder cancer. J Cancer Res Clin Oncol 2018; 144: 1701-1709.

23. Sheng Y, Yu C, Liu Y, Hu C, Ma R, Lu X, Ji P, Chen J, Mizukawa B, Huang Y, Licht JD, Qian Z. FOXM1 regulates leukemia stem cell quiescence and survival in MLL-rearranged AML. Nat Commun 2020; 11: 928.

24. Siveen KS, Prabhu K, Krishnankutty R, Kuttikrishnan S, Tsakou M, Alali FQ, Dermime S, Mohammad RM, Uddin S. Vascular endothelial growth factor (VEGF) signaling in tumour vascularization: potential and challenges. Curr Vasc Pharmacol 2017; 15: 339-351.

25. Talari NK, Panigrahi MK, Madigubba S, Phanithi PB. Overexpression of aryl hydrocarbon receptor (AHR) signalling pathway in human meningioma. J Neurooncol 2018; 137: 241-248.

26. Vasudevan HN, Braunstein SE, Phillips JJ, Pekmezci M, Tomlin BA, Wu A, Reis GF, Magill ST, Zhang J, Feng FY, Nicholaides T, Chang SM, Sneed PK, McDermott MW, Berger MS, Perry A, Raleigh DR. Comprehensive molecular profiling identifies FOXM1 as a key transcription factor for meningioma proliferation. Cell Rep 2018; 22: 3672-3683.

27. Wagner JE, Brunstein CG, Boitano AE, DeFor TE, McKenna D, Sumstad D, Blazar BR, Tolar J, Le C, Jones J, Cooke MP, Bleul CC. Phase I/II trial of StemRegenin-1 expanded umbilical cord blood hematopoietic stem cells supports testing as a standalone graft. Cell Stem Cell 2016; 18: 144-155.

28. Weber DC, Ares C, Villa S, Peerdeman SM, Renard L, Baumert BG, Lucas A, Veninga T, Pica A, Jefferies S, Ricardi U, Miralbell R, Stelmes JJ, Liu Y, Collette L, Collette S. Adjuvant postoperative high-dose radiotherapy for atypical and malignant meningioma: A phase-II parallel non-randomized and observation study (EORTC 22042-26042). Radiother Oncol 2018; 128: 260-265.

29. Xing H, Wang S, Li Q, Ma Y, Sun P. Long noncoding RNA LINC00460 targets miR-539/MMP-9 to promote meningioma 
progression and metastasis. Biomed Pharmacother 2018; 105 : 677-682.

30. Yang X, Shi Y, Yan J, Fan H. Downregulation of FoxM1 inhibits cell growth and migration and invasion in bladder cancer cells. Am J Transl Res 2018; 10: 629-638.

31. Yuan B, Liu Y, Yu X, Yin L, Peng Y, Gao Y, Zhu Q, Cao T, Yang Y, Fan X, Li X. FOXM1 contributes to taxane resistance by regulating UHRF1-controlled cancer cell stemness. Cell Death Dis 2018 9: 562 .

32. Zhang HG, Xu XW, Shi XP, Han BW, Li ZH, Ren WH, Chen PJ, Lou YF, Li B, Luo XY. Overexpression of forkhead box protein M1 (FOXM1) plays a critical role in colorectal cancer. Clin Transl Oncol 2016; 18: 527-532.

33. Zhang Y, Yu R, Li Q, Li Y, Xuan T, Cao S, Zheng J. SNHG1/miR-556$5 \mathrm{p} / \mathrm{TCF} 12$ feedback loop enhances the tumorigenesis of meningioma through Wnt signaling pathway. J Cell Biochem 2020; 121: $1880-1889$ 